\title{
Electrical Performance and Reliability of n-MOSFET's with Gate Dielectrics Fabricated by Different Techniques
}

\author{
Zeng Xu, P. T. Lai, and W. T. Ng \\ Dept. of Electrical and Electronic Engineering, The University of HongKong.
}

\section{INTRODUCTION}

There have been extensive studies on fabricating high-quality and reliable thin gate dielectrics for MOS applications in VLSI technology. Nitrogen incorporation into the gate oxide is one of the promising methods to achieve excellent immunity to hot-carrier degradation, and effective diffusion barrier against dopants. Many techniques have been proposed [1-4], and among these, reoxidized $\mathrm{NH}_{3}$-nitrided $\mathrm{SiO}_{2}$ and $\mathrm{N}_{2} \mathrm{O}$-based dielectrics have received most attention. Compared with $\mathrm{NH}_{3}-$ based processes, the $\mathrm{N}_{2} \mathrm{O}$-based processes have an important advantage in addition to the process simplicity, i.e., the absence of any hydrogen-related species during processing, which are believed to be the cause of an increase in electron traps in the gate oxide [5]. In this paper, electrical characteristics and reliability of n-MOSFETs under DC/AC stress are investigated and results are compared among the devices with gate dielectrics fabricated by different techniques.

\section{EXPERIMENTAL}

n-MOSFETs were fabicated on p-type (100)-oriented silicon wafers $(8 \sim 10 \Omega \mathrm{cm})$ by a conventional polysilicon self-aligned MOS process. Four kinds of gate dielectrics were prepared as shown in Table 1. All gate oxides were finally annealed in $\mathrm{N}_{2}$ at $950^{\circ} \mathrm{C}$ for $25 \mathrm{~min}$. Oxide thickness was measured by $C V$ technique, the value is $94 \dot{A}$ for $N_{2} O$-grown oxide, and $99 \dot{A}$ for other gate oxides. No passivation film was used. Devices with $1 \mu \mathrm{m} / 60 \mu \mathrm{m}$ effective channel length/width were used in this work.

Table 1. Preparation sequences of gate oxide employed in this study

\begin{tabular}{|c|c|c|c|}
\hline sample & oxidation & nitridation & reoxidation \\
\hline$\overline{O X}$ & $\mathrm{O}_{2}, 850^{\circ} \mathrm{C}, 35 \mathrm{~min}$ & -..-- & ------ \\
\hline NO & $\mathrm{O}_{2}, 850^{\circ} \mathrm{C}, 35 \mathrm{~min}$ & $\mathrm{NH}_{3}, 950^{\circ} \mathrm{C}, 35 \mathrm{~min}$ & -....... \\
\hline RONO & $\mathrm{O}_{2}, 850^{\circ} \mathrm{C}, 35 \mathrm{~min}$ & $\mathrm{NH}_{3}, 950^{\circ} \mathrm{C}, 35 \mathrm{~min}$ & $\mathrm{O}_{2}, 950^{\circ} \mathrm{C}, 15 \mathrm{~min}$ \\
\hline $\mathrm{N} 2 \mathrm{OG}$ & $\mathrm{N}_{2} \mathrm{O}, 950^{\circ} \mathrm{C}, 30 \mathrm{~min}$ & -........ & $---\cdot-$ \\
\hline
\end{tabular}

\section{RESULTS AND DISCUSSION}

Drain current and transconductance versus gate drive measured in linear and saturation regions $(\mathrm{Vd}=50 \mathrm{mV}$ and $3.5 \mathrm{~V})$ are shown in Fig.1 and Fig.2 respectively. Devices with control (OX) and $\mathrm{N}_{2} \mathrm{O}$-grown (N2OG) gate oxides exhibit better subthreshold slopes $\left(\sim 125 \mathrm{mV} /\right.$ decade for $\mathrm{N}_{2} \mathrm{O}-$ grown oxide and $\sim 150 \mathrm{mV} /$ decade for control gate oxide) than the NO device ( $250 \mathrm{mV} /$ decade), as can be seen from Fig.1(a). This agrees well with the interface state density values obatined from MOS capacitors using $C V$ techniques. $\left(-1.5 \times 10^{10} \mathrm{~cm}^{-2} \cdot \mathrm{eV}^{-1}\right.$ for $\mathrm{OX}$ and $\mathrm{N}_{2} \mathrm{O}$-grown oxides and $\sim 3 \times 10^{11} \mathrm{~cm}^{-2} \cdot \mathrm{eV}^{-1}$ for NO oxide). Fig.1(b) shows that the $\mathrm{Gm}$ of the device with $\mathrm{N}_{2} \mathrm{O}$. grown gate oxide is improved in both the low and high $\mathrm{Vg}$ regions comparing to the control (OX) device. This result is different from that in the device with $\mathrm{NH}_{3}$-nitrided (NO) gate oxide [1], [6], where $\mathrm{Gm}$ is improved only in the high $\mathrm{Vg}$ region but degraded in the low $\mathrm{Vg}$ region, also shown in Fig.1(b). The degradation of $\mathrm{G}_{\mathrm{m}}$ in NO device in the low $\mathrm{Vg}$ region was attributed to Coulombic 
scattering due to nitridation-induced fixed-charge, interface state charge, and/or near-interface electron trapping [7]. The near-interface bulk electron traps can capture electrons tunneled from the channel regions, and thus reduce the density of channel mobile charge. In addition, those trapped electrons serve as additional Coulombic scattering centers, thus the electron mobility is reduced. One possible reason for $\mathrm{Gm}$ improvement in the low $\mathrm{Vg}$ region for $\mathrm{N} 2 \mathrm{OG}$ device is due to the improved charge trapping property demonstrated by small gate voltage shift during constant current stress [8]. This is also verified by the better stability of N2OG device under channel hotelectron injection as presented in Fig.4. Another possible reason is the effect of residual mechanical stress [1]. $\mathrm{N}_{2} \mathrm{O}$-based oxide is supposed to have less compressive stress due to the compensating tensile stress effect through nitrogen incorporation at the interface. Fig.2(a) and (b) illustrate the improved current drivability (ld) and transconductance $(\mathrm{Gm})$ in the saturation region $(\mathrm{Vd}=3.5 \mathrm{~V})$ for n-MOSFET with $\mathrm{N}_{2} \mathrm{O}$-grown gate oxide, as compared to the control and NO devices. Similar results were reported in [9] for n-MOSFET with $\mathrm{N}_{2} \mathrm{O}$-nitrided gate oxide. It is worth noting that Gm starts to degrade beyond $\mathrm{Vg}-\mathrm{V}_{\mathrm{t}} \sim 3 \mathrm{~V}$ for the $\mathrm{N} 2 \mathrm{OG}$ device. This may result from $\mu_{\mathrm{n}, \text { eff }}$ degradation at higher vertical field [10]. In Fig.3, better characteristics of N2OG device than OX device were confirmed, especially under high $\mathrm{Vg}$. Even under low $\mathrm{Vg}$, the drivability is comparable to that of the pure gate oxide sample. This is different from the RONO device, which exhibits lower current drivability under low gate drive voltage [11].

Presented in Fig. 4 is the stress-time dependence of $V_{t}$ and $G_{m}$ instability induced by channel hot-carrier stress (CHCS). The stress condition was chosen to result in channel hot-electron injection into the gate oxide $\left(V g=V_{d}=7 V\right) . V_{t}$ shift is much smaller for the RONO and N2OG devices than the control device, implying electron trapping is significantly suppressed by the nitridation steps. The $n$-MOSFET with $\mathrm{N}_{2} \mathrm{O}$-grown gate oxide shows the least $\Delta \mathrm{G}_{\mathrm{m}}$, indicating improved interface hardness against $\mathrm{CHCS}$. The improved interface hardness and suppressed electron trapping are believed to be due to interfacial strain relaxation as well as substitution of $\mathrm{Si}$ $\mathrm{O}$ bonds with stronger $\mathrm{Si}-\mathrm{N}$ bonds through the formation of oxynitride $\left(\mathrm{SiO}_{\mathrm{x}} \mathrm{N}_{\mathrm{y}}\right)$ [12], and the elimination of $\mathrm{H}$-related species during the $\mathrm{N}_{2} \mathrm{O}$ nitridation process.

Fig.5 depicts $V_{t}$ shifts for $O X, R O N O$ and $\mathrm{N}_{2} \mathrm{OG}$ gate oxide devices subjected to AC stress and then DC stress continuously. As can be seen clearly that $\mathrm{N}_{2} \mathrm{O}$ device has very stable $\mathrm{V}_{1}$ under the whole combined $A C / D C$ stress, while $O X$ device has a slight $V_{1}$ increase $(-37 \mathrm{mV})$ in the $A C$ stress session, but a very large increase in $V_{t}(-410 \mathrm{mV})$ in the subsequent DC stress, which results from channel hot electron injection. It should be noted that the $V_{1}$ shift here during DC stress session is even larger than that shown in Fig.4(a) $(\sim 210 \mathrm{mV})$ for fresh OX device, although lower stress voltage $\left(\mathrm{Vg}=\mathrm{V}_{\mathrm{d}}=5 \mathrm{~V}\right)$ was employed, suggesting large amount of electron traps was created during the $\mathrm{AC}$ stress in the pure thermal gate oxide. On the other hand, the same $\mathrm{AC}$ stress did not generate any significant amount of electron traps in the RONO and $\mathrm{N}_{2} \mathrm{O}$-grown gate oxide, indicating device reliability with nitrided gate oxides is also enhanced under dynamic stress. Again, $\mathrm{N}_{2} \mathrm{O}$-grown oxide behaves even better than reoxidized $\mathrm{NH}_{3}$-nitrided oxide.

\section{CONCLUSION}

$\mathrm{N}_{2} \mathrm{O}$ nitridation is a more promising technique to incorporate nitrogen into gate oxide than $\mathrm{NH}_{3}$ nitridation both from the view of electrical performance and stability under $\mathrm{CHCS}$ and dynamic stress.

\section{REFERENCES}

[1] H. S. Momose, T. Morimoto, K. Yamabe, and H. Iwai, "Relationship between mobility and residual-mechanical-stress as measured by Raman spectroscopy for nitrided-oxide-gate MOSFETs," in IEDM Tech. Dig., 1990, p65. 
[2] P. J. Wright, A. Kermani, and K. C. Saraswat, "Nitridation and post-nitridation anneals of $\mathrm{SiO}_{2}$ for ultrathin dielectrics," IEEE Trans. Electron Device, vol.37, p.1836, 1990.

[3] T. Ito, T, Nakamura, and H. Ishikawa, "Advantages of thermal nitride and nitroxide gate films in VLSI process, " IEEE Trans. Electron Device, vol.29, p.498, 1982.

[3] Z. H. Liu, P. T. Lai, and Y. C. Cheng, "Characterization of charge trapping and high-field endurance for 15 -nm thermally nitrided oxides," IEEE Trans. Electron Device, vol.38, p.344, 1991.

[4] H. Hwang, W. Ting, D. L. Kwong, and J. Lee, "Electrical and reliability characteristics of ultrathin oxynitride gate dielectric prepared by rapid thermal processing in $\mathrm{N}_{2} \mathrm{O}$," in IEDM Tech. Dig., 1990, p.421.

[5] T. Hori, etc., "Demands for submicron MOSFETs and nitrided oxide gate-dielectrics," Extended Abstracts of the 21th conference on Solid State Devices and Materials, pp.197-200, 1989.

[6] T. Hori, "Deep-submicron nitrided-oxide CMOS technology for 3.3-V operation," in IEDM Tech. Dig., 1990, p.837.

[7] M. A. Schmidt, etc., "Inversion layer mobility of MOSFET's with nitrided oxide gate dielectrics," IEEE Trans. Electron Device, vol.35, p.1627, 1988.

[8] Z. H. Liu, H. J. Wann, P. K. Ko, C. Hu, and Y. C. Cheng, "Improvement of charge trapping characteristics of $\mathrm{N}_{2} \mathrm{O}$-annealed and reoxidized $\mathrm{N}_{2} \mathrm{O}$-annealed thin oxides," IEEE Electron Device Lett., vol.13, p.519, 1992.

[9] J. Ahn, W. Ting, and D. L. Kwong, "Furnace nitridation of thermal $\mathrm{SiO}_{2}$ in pure $\mathrm{N}_{2} \mathrm{O}$ ambient for ULSI applications," IEEE Electron Device Lett., vol.13, p.117, 1992.

[10] C. G. Sodini, P. K. Ko, and J. L. Moll, "The effect of high fields on MOS devices and circuit performance," IEEE Trans. Electron Device, vol.31, p.1386, 1984.

[11] H. S. Momose, etc., "Very lightly nitrided oxide gate MOSFETs for deep-sub-micron CMOS devices," in IEDM Tech. Dig., 1991, p.359.

[12] M. M. Moslehi, K. C. Saraswat, and S. C. Shatas, "Rapid thermal nitridation of $\mathrm{SiO}_{2}$ for nitroxide thin dielectrics," Appl. Phys. Lett., vol.47, p.1113, 1985.

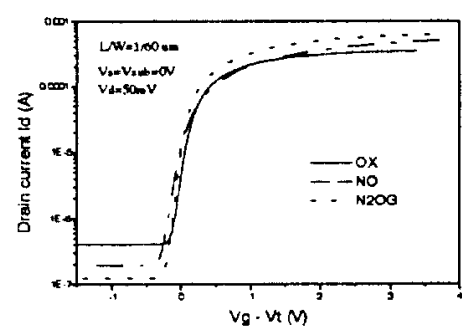

(a)

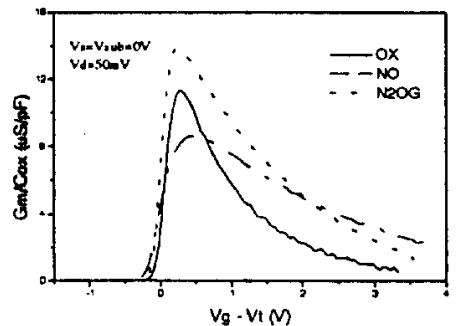

(b)

Fig.1. (a) Id and (b) $\mathrm{Gm}$ measured at linear region $(\mathrm{Vd}=50 \mathrm{ml}$; as a function of gate drive for $\mathrm{n}$-MOSFETs (Leff $/ \mathrm{Weff}=1.0 / 60 \mu \mathrm{m}$ ) with control( $\mathrm{OX}$ ), $\mathrm{NH}_{3}$-nitrided (NO), and $\mathrm{N}_{2} \mathrm{O}$-grown (N2OG) thermal gate oxides. 


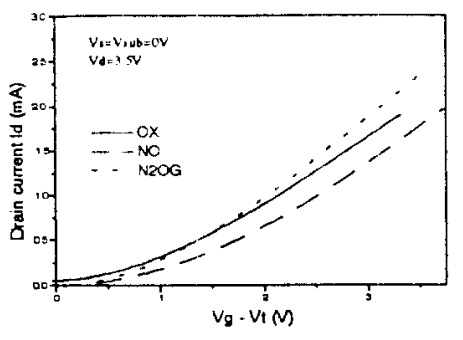

(a)

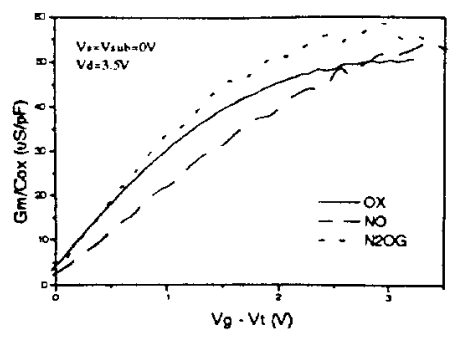

(b)

Fig.2. (a) Id and (b) $\mathrm{Gm}$ measured at saturation region ( $\mathrm{Vd}=3.5 \mathrm{~V}$ ) for n-MOSFETs with control (OX), NH3-nitrided (NO), and $\mathrm{N} 2 \mathrm{O}$-grown ( $\mathrm{N} 2 \mathrm{OG}$ ) thermal oxides.

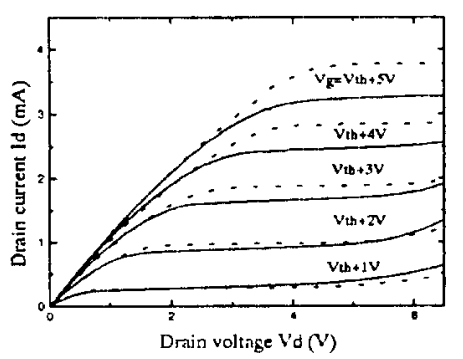

Fig.3. Id - Vd characteristics. Dot lines for N2OG device, and solid lines for control $(O X)$ device.

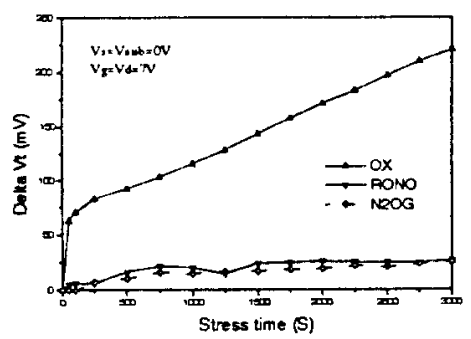

(a)

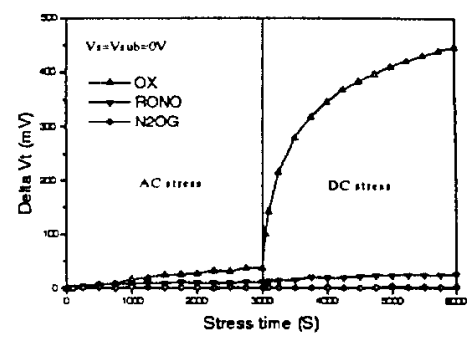

Fig.5. $V_{1}$, shifis versus stress time during $A C$ stress and subsequent DC stress for $\mathrm{OX}$, RONO, and $\mathrm{N} 2 \mathrm{OG}$ devices. For $\mathrm{AC}$ stress, $\mathrm{Vd}=5 \mathrm{~V}$ and $\mathrm{Vg}$ was pulsed between $\mathrm{Vgl}=0 \mathrm{~V}$ and $\mathrm{Vgh}=5 \mathrm{~V}$ at a frequency of $100 \mathrm{kHz}$ with $50 \%$ duty cycle squarewave. For DC stress, $\mathrm{Vg}=\mathrm{Vd}=5 \mathrm{~V}$

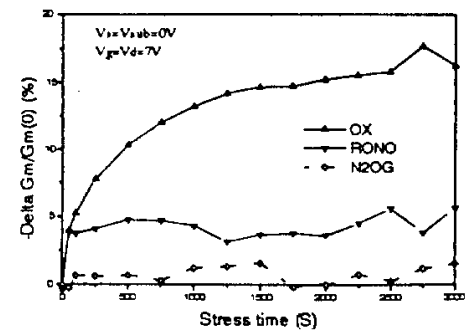

(b)

Fig.4. Stress-time dependence of (a) $V_{t}$ shift and (b) $G_{m}$ degradation under channel hot electron stress $\left(\mathrm{Vg}=\mathrm{Vd}=7 \mathrm{~V}\right.$ ) for $\mathrm{n}$-MOSFETs $($ Leff $/ \mathrm{Weff}=1 / 60 \mu \mathrm{m})$ with control $(\mathrm{OX})$, reoxidized $\mathrm{NH}_{3}$-nitrided (RONO), and $\mathrm{N}_{2} \mathrm{O}$-grown ( $\mathrm{N} 2 \mathrm{OG}$ ) thermal oxides. 